Note: This paper is now "in press" at Social and Personality Psychology Compass.

The final published version may differ slightly. For an up-to-date APA citation, see:

www.nickholtzman.com/publications

\title{
The Story of "I" Tracking:
}

\section{Psychological Implications of Self-Referential Language Use}

\author{
Amunet K. Berry-Blunt ${ }^{1}$ and Nicholas S. Holtzman ${ }^{1}$ \\ ${ }^{1}$ Department of Psychology, Georgia Southern University \\ M. Brent Donnellan² \\ ${ }^{2}$ Department of Psychology, Michigan State University \\ Matthias R. Mehl ${ }^{3}$ \\ ${ }^{3}$ Department of Psychology, University of Arizona
}

\begin{abstract}
Author Note
We thank Jamie Pennebaker and Dalibor Kučera for their helpful feedback on a previous version of this manuscript.

We have no conflicts of interest to disclose. Correspondence concerning this article should be addressed to Nick Holtzman, Department of Psychology, P.O. Box 8041, Georgia Southern University, Statesboro, GA, 30460, United States. Email: nick.holtzman@ gmail.com
\end{abstract}




\begin{abstract}
We review extant research on the psychological implications of the use of first-person singular pronouns (i.e., "I-talk"). A common intuition is that I-talk is associated with an overly positive, highly agentic, and inflated view of the self-including arrogance, self-centeredness, and grandiose narcissism. Initial (small-sample) research provided evidence that frequent I-talk was associated with grandiose narcissism. More recent (large-sample) research, however, has found that the correlation is near zero. Frequent I-talk is, however, positively correlated with depressive symptoms, in particular, and negative emotionality (i.e., neuroticism), more broadly. Frequent Italk is also positively related to the neurotic variety of narcissism called vulnerable narcissism. In addition, frequent I-talk has a positive association with sociodemographic characteristics such as (lower) status, (younger) age, and (female) gender; I-talk has a conditional association with truth-telling and authenticity - a correlation that appears to hinge on context. This review summarizes the literature on I-talk, provides some speculations about the emergent psychological meanings of I-talk, and provides a guide for future research.
\end{abstract}

Keywords: I-talk; language use; LIWC; personality; self-referencing; self-awareness; individual differences 


\section{The Story of "I" Tracking:}

\section{Psychological Implications of Self-Referential Language Use}

All I can hear I me mine, I me mine, I me mine, Even those tears I me mine, I me mine, I me mine [...]

Flowing more freely than wine, All through your life I me mine.

—George Harrison, The Beatles (1970)

\section{Preface: Importance}

In the lyrics of their iconic song "I me mine", The Beatles lamented an omnipresent selffocus in contemporary society, which they equated with people excessively using first-person singular pronouns. Indeed, it is a common belief that frequently using "I", "me", and "mine" or so-called "I-talk" reflects heightened narcissism (McWhorter, 2017). In this article, we review the psychological correlates of frequent linguistic self-referencing, or I-talk (Ireland \& Mehl, 2014). This is an important topic in personality and social psychology, dating back to the writings of William James (1890) and George Herbert Mead (1934). These influential philosopher-psychologists contemplated how language related to selfhood (Goodman, 2017), including I-talk. More recent empirical research sheds light on how personality dispositions and self-related processes are manifested in verbal tendencies (Kern et al., 2013), and it provides insights into cues for more accurately perceiving and assessing people. Along the way, the story of the psychological correlates of I-talk exemplifies the process of how an empirical literature develops. Like many good stories, this involves a few interesting plot twists. 
Perceivers tend to infer that I-talk communicates arrogance, self-centeredness, and narcissism. For example, media reports suggest that I-talk reflects a loss of humility in United States presidents (Cary, 2009), as was the case when a popular blog author asked of Barack Obama's presumed excessive I-talk, “...is this the beginning of the end of any humility on his part?” Linguistics professor Mark Liberman argues that it is routinely taken as obvious that I-talk reflects narcissistic traits (Liberman, 2014) on his Language Log blog. Liberman also noted that Obama was using I-words less frequently than previous presidents (Liberman, 2014), yet conservative pundits saw Obama as excessively using I-words. In one blog post, he wrote that Obama is viewed by conservative pundits as "arrogant" and "uppity" because of his presumed frequent I-talk (Liberman, 2009). These pundits, however, are not alone in this assumption. Researchers also make the inference that I-talk indicates narcissism (Chatterjee \& Hambrick, 2007; DeWall, Pond, et al., 2011).

Narcissism is the subject of intense empirical and theoretical interest in developmental (Hill \& Roberts, 2018; Thomaes et al., 2009), clinical (Miller et al., 2017), personality (Campbell \& Miller, 2011), and social psychology (Krizan \& Herlache, 2018). In this literature, there is a distinction between grandiose and vulnerable expressions of narcissism (Krizan \& Herlache, 2018; Miller et al., 2011; Wright \& Edershile, 2018), and we elaborate on this distinction in the following section about vulnerable narcissism. Chapter one of the I-talk story begins as Raskin and Shaw (1988) studied the association between pronoun use and grandiose narcissism. Before the first chapter, however, we provide a "prologue" about why and how personality psychologists study natural language use.

\section{Prologue: Personality Psychology, Language Use, and Effect Sizes}


Idiosyncrasies in natural word use have increasingly fascinated personality researchers (e.g., Fast \& Funder, 2010; Park et al., 2015; Pennebaker \& King, 1999; Yarkoni, 2010). Personality psychology often focuses on the ways that people differ from one another in their characteristic patterns of thinking, feeling, and behaving — that is, in their individual differences (Funder, 2001; McAdams \& Pals, 2006). A focus on language use in personality psychology therefore makes sense because (a) people have characteristic ways of verbalizing their experiences that differ from person to person; and (b) these differences in word use are thought to reveal something deeper about individuals' underlying personalities (Ireland \& Mehl, 2014). Many individual difference constructs interest personality psychologists. Here, we focus on a few that have received significant attention in the literature about personality and first-person singular pronoun use. Understanding individual differences in word use is complicated. Few people believe that how people talk is completely determined by their personalities. Language use conveys information about communication intentions, the situation, temporary mood states, dynamics of social interactions, and sometimes just random factors. Nevertheless, personality researchers have some general expectations for how strongly personality attributes may be associated with pronoun usage.

Most correlations that psychological scientists study are far from perfect, and this applies to the literature about personality and pronoun use. Many associations will be between -.20 and .20. This is reasonable because language use is multiply determined (i.e. many factors influence how a person uses words in a sentence) and that limits the size of any single effect (see Ahadi \& Diener, 1989; Funder \& Ozer, 2019, provide a current discussion of effect sizes). This background knowledge serves as a prologue to the saga about personality and pronoun use, which we turn to now. 


\section{Chapter 1: Is Grandiose Narcissism Really Manifested in Frequent I-Talk?}

Narcissism plays a central role in Chapter 1. Sub-clinical narcissism involves a tendency to act in self-centered ways (Buss \& Chiodo, 1991), to experience a high need of validation (Baumeister \& Vohs, 2001), and to have a need for cultivating a positive public image or facade (Carlson et al., 2011), particularly in short-term encounters (Campbell \& Campbell, 2009). Narcissistic behavior is commonly represented in two facets (Back et al., 2013; Wink, 1991), typically labeled grandiose narcissism and vulnerable narcissism (Miller et al., 2011) — the latter being important for a subsequent chapter. Compared to vulnerable narcissism, grandiose narcissism is more often studied in social-personality psychology, typically using measures like the Narcissistic Personality Inventory (Raskin \& Hall, 1981; Raskin \& Terry, 1988; Raskin \& Hall, 1979) and the Narcissistic Admiration and Rivalry Questionnaire (Back et al., 2013), and grandiose narcissism aligns with the typical lay view of narcissism - that narcissism is about inflated self-views (Baumeister \& Vohs, 2001) and remarkable displays of vanity (Robins \& John, 1997). Grandiose narcissism is associated with higher self-esteem (Miller et al., 2011), as well as an embellishment of one's abilities (Paulhus \& Williams, 2002; Sedikides, 2020), and an unrealistic sense of superiority (Raskin \& Terry, 1988). Compared to people low on grandiose narcissism, people who score high on this trait tend to have higher agency (Miller et al., 2011), higher dominance (Dowgwillo \& Pincus, 2017), and they have somewhat fewer concerns for maintaining interpersonal relationships, reflected in lower agreeableness or higher antagonism (Miller et al., 2011; Paulhus, 2001). This trait profile manifests in exhibitionism (Weiser, 2015) and obnoxious behavior, such as somewhat more frequent cursing (Holtzman et al., 2019). Collectively, these descriptions indicate that grandiose narcissism involves a constellation of 
egocentric attributes that reflect excessive self-focused attention. Given this self-focus, it is natural to predict that grandiose narcissism should manifest in more frequent I-talk.

Raskin and Shaw (1988) were the first investigators to test the presumed positive correlation between narcissism and I-talk. They asked each participant to give a five minute recorded speech on a self-selected topic. This part of the design allowed participants considerable freedom and presumably offered an opportunity for researchers to see which participants expressed narcissistic tendencies. The researchers counted the first person singular pronouns that participants used. Corroborating the idea that narcissists frequently use I-talk, these data showed a relatively moderate positive correlation $(r=.26)$ between grandiose narcissism and first-person singular pronoun use. A major caveat is that their sample consisted of just 24 men and 24 women — a sample size that would be considered insufficient by current standards (Schonbrodt \& Perugini, 2013). Small samples not only elevate the risk that researchers will fail to capture existing true effects that are undetectable (yielding false negatives), but they also pose a risk of mistakenly detecting effects where there are none in reality (i.e., yielding false positives). Small sample sizes like this provide imprecise estimates and this is especially true for the Raskin and Shaw study $(N=48 ; r=.26 ; 95 \% \mathrm{CI}=[-.03, .51])$. Interestingly, Raskin and Shaw (1988) reported the $p$-value for the association between narcissism and I-talk as " $p<.05$ ” in their original paper (see also: Carey et al., 2015, Footnote 1). This statement means that the coefficient fell below the conventional level of statistical significance $(p<.05)$. Based on the sample size and the reported correlation coefficient, however, the two-tailed $p$-value is .074, suggesting that Raskin and Shaw decided that the hypothesis had sufficient intuitive appeal that it warranted directional hypothesis testing as well as one-tailed tests. By still quite a loose standard of being less than .05 using a two-tailed test, 
however, the original Raskin and Shaw effect is not evident (cf. Benjamin et al., 2018, for an argument that .005 is a more appropriate threshold).

Despite these concerns with the statistical evidence in the original paper, the Raskin and Shaw (1988) results had been accepted by some researchers (Chatterjee \& Hambrick, 2007; DeWall, Buffardi, et al., 2011; cf. Van Scotter II, 2020). For instance, in a study of CEOs, Chatterjee and Hambrick (2007) defined narcissism using five criteria, with frequent I-talk being one of them (i.e., 20\% of the definition). DeWall, Buffardi, and colleagues (2011) defined narcissism in social media posts via frequent I-talk in online communications (i.e., 100\% of the definition). Thus, following Raskin and Shaw (1988), some psychological scientists used I-talk as a direct behavioral operationalization of narcissism, sometimes even treating these two as isomorphic —one in the same.

Although it seems tempting to posit that individual differences in I-talk serve as a marker of grandiose narcissism, the next part of this story offers a twist. Carey et al. (2015) tested the claim linking I-talk to grandiose narcissism in a comprehensive, large-sample, five-lab collaboration $(N=4,811)$. This was a multi-sample, multi-measure integrative analysis using two languages (English and German), and a range of communication contexts (writing or talking about a personal vs. impersonal topic; writing or talking in a private vs. public context). Grandiose narcissism was effectively unassociated with I-talk ( $r=.01,95 \%$ CI $[-.02 ; .04])$. Interestingly, the researchers simulated that any random small subsample of 50 participants from the full sample of nearly 5,000 participants could easily yield an (artificially inflated) estimate comparable to the magnitude of the one obtained by Raskin and Shaw $(r=.26)$, merely due to chance. Collecting large samples to obtain stable effect size estimates tends to solve this problem. Despite the Carey (2015) results, however, some researchers continue to use I-talk as a 
measure of narcissism in research published after Carey et al.'s paper (Buttice \& Rovelli, 2020; Capalbo et al., 2018; Yang et al., 2018). The empirical support for the validity of using "I me mine" to indicate grandiose narcissism (Raskin \& Shaw, 1988), however, is now outdated.

\section{Chapter 2: If Not Grandiose Narcissism, Then What?}

The finding that grandiose narcissism is virtually unrelated with I-talk, of course, prompts the question about other potential correlates of I-talk. Some early studies of I-talk were motivated by an interest in internalizing psychological problems like depressive symptoms and the negative affective consequences of objective self-awareness, which also involve self-focus (Silvia \& Duval, 2001; Smith \& Greenberg, 1981; Wicklund \& Duval, 1971). Continuing in this theoretical tradition, an important preamble to the next chapter of our story was the discovery of an association between I-talk and suicide (Stirman \& Pennebaker, 2001). This now-classic study compared the language of famous poets, who either did or did not die by suicide (Stirman \& Pennebaker, 2001). Intriguingly, the poems of suicidal poets contained more I-talk than the poems of non-suicidal ones (Stirman \& Pennebaker, 2001, Table 1) - a tragic manifestation of an unhealthy self-focus. Although the sample was tiny $(N=18)$, many poems (i.e., $\sim 300)$ were analyzed (which provides some confidence in the reliability of the findings, but does not ultimately offset the small sample size). These results therefore provided some tentative and preliminary evidence for maladaptive self-preoccupation (and social isolation) in suicidal individuals - a prediction in line with theory about the negative influence of self-awareness (Silvia \& Duval, 2001). Moreover, it is useful to note that grandiose narcissism is typically negligibly correlated with individual differences associated with internalizing problems, at least overall (Hill \& Roberts, 2011). 
Stirman and Pennebaker (2001) pointed to a different correlate of I-talk, namely depression (Fast \& Funder, 2010). Depression is associated with suicide and suicidal ideation, plus depression is one of the most prevalent mental disorders worldwide (W.H.O., 2020). Studies of suicidality motivated projects on depression and I-talk (e.g., Brockmeyer et al., 2015), which were in turn meta-analyzed by Edwards and Holtzman (2017), who revealed a non-trivial, statistically significant correlation $(r=.13)$ between I-talk and depressive symptoms, from a sizable sample (total $N=3,758$ ). This meta-analysis helped summarize the literature linking Italk to depression. Thereafter, research examined how language use on social media correlated with depression. For example, research shows that first-person singular pronouns can predict a diagnosis of clinical depression by up to three months (Eichstaedt et al., 2018) and a recent daily diary study with clinically depressed adults corroborated this idea (Krejtz et al., 2020; see also: O'Dea et al., 2017). Having honed in on a reliable correlate of self-focused languagedepression-one correlate of I-talk was starting to come into focus.

Depression entails numerous symptoms related to negative emotions (Bernard et al., 2016). One key investigation built on the Carey et al. (2015) model of combined data from different research laboratories: Tackman et al. (2019) found I-talk to be robustly related to depression $(r=.10)$, confirming the earlier Edwards and Holtzman (2017) meta-analysis. The association with I-talk extended to a general tendency towards neuroticism or negative emotionality ( $r=.13$; Tackman et al., 2019). Neuroticism includes depressive tendencies and excessive self-consciousness (Widiger \& Oltmanns, 2017). An individual with high levels of neuroticism tends to experience dissatisfaction across a range of life settings-effects that over time can erode a person's physical health (Widiger \& Oltmanns, 2017). The integrative analysis by Tackman et al. (2019) included a large sample (total $N=4,754$ ), and it explored numerous 
verbal contexts (e.g., personal, impersonal). The study used different measures across labs to assess depression, including different versions of the Beck Depression Inventory (Beck et al., 1996; Dozois et al., 1998) and the Center for Epidemiologic Studies Depression Scale (Radloff, 1977). Zero-order correlations were generally consistent across different contexts (except impersonal writing). Critically, the authors used an approach to test whether the depression and I-talk association was still evident when neuroticism was in the multiple regression model. Neuroticism is a broader dispositional tendency than depressive symptoms, so it is useful to test whether depression is a unique correlate of I-talk after considering neuroticism. The researchers used different measures of the Big Five, such as the Big Five Aspect Scales (BFAS; DeYoung et al., 2007) to measure negative emotionality (AKA neuroticism). They found that adding neuroticism as a predictor ended up decreasing the depression association, whereas the reverse was not the case. This shows that the specific depression and I-talk association is substantially subsumed within the broader association between neuroticism and I-talk (Tackman et al., 2019), and it indicates I-talk might reflect a broader dispositional tendency towards feelings of distress and even susceptibility to the internalizing spectrum of psychopathology (Lyons et al., 2018). This possibility is a topic of ongoing research. This finding for neuroticism and I-talk also prompted researchers to evaluate the possibility that a variety of narcissism called vulnerable narcissism was positively associated with I-talk.

\section{Chapter 3: Grandiose Narcissism is Not Related to I-Talk, But How About Vulnerable Narcissism?}

Now comes one of the bigger plot twists in the I-talk saga, featuring the reappearance of narcissism. Previous I-talk research focused on grandiose narcissism, and that seemed like an 
empirical dead-end. However, the neuroticism findings from Tackman et al. (2019) prompted researchers to consider other varieties of narcissism. One variety, vulnerable narcissism (Miller et al., 2011), is strongly identified with neuroticism (Krizan \& Herlache, 2018; Miller et al., 2011). Thus, research by Tackman et al. (2019) suggested focusing on whether this neurotic version of narcissism is associated with I-talk, even if grandiose narcissism is not.

Vulnerable narcissism involves a combination of self-focused attention and psychological distress and is related to neuroticism or negative emotionality (Miller et al., 2011). Whereas grandiose narcissism relates to socially-domineering traits (Jones \& Paulhus, 2014), vulnerable narcissism "reflects a defensive and insecure grandiosity that obscures feelings of inadequacy, incompetence, and negative affect" (Miller et al., 2011); it is typically measured using scales like the Hypersensitive Narcissism Scale (Hendin \& Cheek, 1997). Recently, Dixon et al. (2020) confirmed in a pre-registered study $(N=1,253)$, which involved digitally recording predictions before data collection began, that vulnerable narcissism is positively associated with I-talk ( $r=$ .12), almost to the same extent as negative emotionality.

When both neuroticism and vulnerable narcissism were entered into a regression analysis predicting I-talk, however, the partial regression weights suggested statistical redundancy. This often happens for correlated predictors (neuroticism and vulnerable narcissism were correlated approximately $r \approx .60$ ). The standardized regression weight for neuroticism $\left(\beta_{\text {partial }} \approx .10\right.$ ) remained statistically significant, whereas the standardized regression weight for vulnerable narcissism $\left(\beta_{\text {partial }} \approx .05\right)$ was no longer significant. So, the question remains as to whether this vulnerable narcissism association is just about the general finding that neuroticism is a reliable correlate of I-talk (Tackman et al., 2019). This research is also ongoing. 


\section{Chapter 4: Sociodemographic Correlates of I-Talk}

A fourth chapter in story of I-talk focuses on the "supporting actors" in the periphery of the saga of how personality relates to I-talk, that is, sociodemographic correlates of first-person singular pronoun use. Although not focused on personality, this work provides further clarity for characterizing the psychological meaning of I-talk. Specifically, a robust literature reveals how low social status and low power (collectively, "low ranking") manifest in more frequent use of Italk. Kacewicz et al. (2013) provided evidence for this correlation in four small samples (see their Table 2). Using a wide array of methods (e.g., instant messenger records, letters written by U.S. soldiers), people who used frequent I-talk tended to be low ranking; other evidence supports this notion (Cassell et al., 2006)—powerful people tend to use less I-talk. Additional demographic variables, such as age and gender are related to I-talk in particular ways. Compared to older adults, younger adults use more I-talk (Kern et al., 2014; Pennebaker \& Stone, 2003); compared to men, women use more I-talk (Newman et al., 2008). Thus, one emerging theme in this literature is that people who have traditionally held powerful, high-status positions tend to use less I-talk, whereas people who have traditionally held low-status and subordinate positions tend to use more I-talk.

This theme fits nicely with the two narcissism effects discussed earlier: The lower-status version of narcissism, which is sometimes pejoratively referred to as "failed" narcissism (Back \& Morf, 2018; Czarna et al., in press)—namely, vulnerable narcissism—is positively associated with I-talk, at least in the form of a positive and non-trivial zero-order correlation (Dixon et al., 2020), whereas the higher-status version of narcissism — grandiose narcissism — is not significantly associated with I-talk, as the two variables have a near-zero correlation (Carey et al., 2015; Dixon et al., 2020). All in all, I-talk seems to be partially tracking self-awareness 
related to low social status. Figure 1 summarizes the key correlates of I-talk that we have reviewed so far.

\section{Cliff-hanger: Honesty versus Deception}

The story thus far suggests that grandiose narcissism is not a robust correlate of I-talk, while neuroticism and vulnerable narcissism are positively correlated with I-talk. An additional "supporting actor" in the story is honesty, but this part of the story remains unfinished. It turns out to be a bit of a cliff-hanger, and sets up future chapters of the story of I-talk. The logic is as follows: To withstand the psychological costs of lying, liars may psychologically distance themselves from their tales; conversely, honest people may be more inclined to remain psychologically close to (or "own") their narratives (Newman et al., 2003), perhaps indicating authenticity. The self-distancing in lying may therefore involve reducing the use of first-person singular pronouns (Hauch et al., 2015). Hauch et al. (2015) meta-analyzed over 20 studies, including key papers such as Hancock et al. (2007), revealing a near-zero correlation—and thus was not supportive of this idea; the Hedges's $g$ was -.06 (see their Table 1, Research Question 4, row label 23), which is not statistically significant $(p>.05)$. Follow-up analyses, in contrast, pointed to a positive and statistically significant relationship (Hedges's $g=.34,95 \%$ CI [.20, .49]) between first-person singular pronouns and honesty (see their Table 4, row label 21). In combination, results from this meta-analysis suggest that the honesty-deception dimension may correlate with first-person pronoun use in context-specific ways. The association between I-talk and honesty needs to be replicated, perhaps using the large sample collaborative approach found in Carey et al. (2015) and Tackman et al. (2019), given that most of the studies in this literature 
use small sample sizes. Still, honesty and authenticity might be featured as the I-talk story continues to unfold.

\section{Synthesis: The Psychology of I-Talk}

In an attempt to elaborate on the results depicted in Figure 1, we provide a detailed and to some extent speculative description of the psychological correlates of I-talk in this section. People who less frequently use I-talk are more emotionally stable (Tackman et al., 2019), acquisitive (Kacewicz et al., 2013), powerful (Kacewicz et al., 2013), esteemed (Kacewicz et al., 2013), and less open-minded (Tackman et al., 2020); we speculate that they are also more confident and resolute. People who more frequently use I-talk tend to be more emotionally vulnerable (Dixon et al., 2020; Tackman et al., 2019), resentful (Dixon et al., 2020), report more depressive symptoms (Edwards \& Holtzman, 2017; Tackman et al., 2019), and seem more preoccupied (Dixon et al., 2020); in addition, we speculate that they are more down-to-earth and serious. We therefore suggest that I-talk may be a linguistic device that facilitates processing negative emotions (e.g., after some important and negative self-relevant information is obtained) given that negative emotions often narrow attention to the self to motivate action tendencies, whereas positive emotions tend to be associated with outward engagement (e.g., the broadenand-build model; Fredrickson, 2001). Negative emotional experiences are an inevitable part of life but chronically experiencing and expressing negative feelings may prove unwise and ultimately maladaptive (Grossmann et al., in press). Altogether, we suggest that a chronic excessive use of I-talk can index habitual self-conscious emotional instability (O'Dea et al., 2017; Stirman \& Pennebaker, 2001). 
We believe that the personality processes involved in self-focus are important for understanding the results in Figure 1 (Alban \& Groman, 1976). Thinking about personality processes and mechanisms may help elucidate potential points of intervention. In particular, "decentering" might enable individuals to feel a subtle sense of contentment (Kross et al., 2014; Nook et al., 2020), as strong emotions may be allayed. Decentering involves directing attention away from the self toward the external world. Focusing on others and the outside world (rather than on oneself) may effectively reduce the intensity of negative emotions for oneself. Taking a distanced view of oneself — decentering - may allow people to manage not only their emotional states (Nook et al., 2020; Orvell et al., 2019; Quoidbach et al., 2010) but we acknowledge that, at this point, this is really just our data-free attempt at "connecting the dots" and telling the story. If regularly used, decentering might potentially change personality traits, such as neuroticism and emotional volatility (Roberts et al., 2017; Seraj et al., 2021) if such de-centering processes were repeatedly enacted over time and across multiple situations.

\section{Preview: The Future of I-Talk Research}

The science of "I" tracking is fascinating, and researchers have made enormous progress since the original Raskin and Shaw (1988) study. The contemporary literature emphasizes large samples and replication. However, it also tends to emphasize between-person distinctions and large trait dimensions. We think future research would benefit from (a) identifying the smaller psychometric units (e.g., trait facets, nuances, and items) that best capture I-talk, (b) exploring within-person variability in I-talk and its correlates (e.g., Sun et al., 2020), (c) examining I-talk and its associations across psychologically different communication contexts (Mehl et al., 2012), and (d) comparing the correlates of I-talk across cultures (Kučera, 2020). 
Psychometricians might consider doing a more fine-grained analysis of the factors, facets, nuances, and items that capture I-talk. Some work in personality psychology has demonstrated the utility of looking at smaller analytic units (such as Big Five items; e.g., Elleman et al., 2020). Stable estimates are likely to emerge in big data. This type of approach could help create comprehensive and refined profiles of I-talk (and other LIWC categories).

Moreover, current personality research recognizes that variation within people for emotional states is an important complement to the traditional focus on between-person differences in dispositions (or typical ways of thinking and feeling). Regarding within-person variability, one sample ( $N=185$ participants; 1,579 observations), explored by Sun et al. (2020), pointed to a general lack of within-person effects linking I-talk to negative emotion (see Sun et al., 2020, Table 3). We suspect that the near-zero effects may be a result of context-dependent emergence of the correlations. If neuroticism drives the association between I-talk and negative affect, then we would expect that this would manifest primarily in private or intrapsychic contexts (where rumination is typical), but not necessarily in social contexts; some recent work is consistent with this idea (Klauke \& Kauffeld, 2020). These hypotheses have an empirical foundation to build upon (Mehl et al., 2012), and we hope that they are tested soon.

Some findings must still be reconciled; not all research findings are in line with our broad integration here. For example, one large sample study found that in emergencies, I-talk unexpectedly decreases (Guntuku et al., 2020); because this was in a semi-public context (Facebook), it suggests that I-talk may not be the best marker of negative emotionality in public communication contexts. One speculation is that people respond to emergency situations with self-distancing or decentering as part of an adaptive psychological "shock reaction" that (perhaps adaptively) prevents one from becoming emotionally overwhelmed (Cohn et al., 2004). We think 
it is important to emphasize that much work remains to be done to further integrate the literature on I-talk and affect, and we think attention to context will be necessary (as appears to be the case for honesty-deception; Hauch et al., 2015). As we noted in the opening of this review, language use is multiply determined and almost certainly involves interactions between psychological processes and contextual features.

Finally and consistent with our concern with context, most research on I-talk (and language use more broadly) has been conducted on English-speaking participants. Languages differ in important ways with respect to grammatical constraints, including with respect to whether the use of an explicit personal pronoun is required in a sentence or is optional (and conveyed via the declinated verb). Kučera et al. (2018) recently found in a study using the Czech language, a so-called "pronoun-drop" language in which personal pronoun use is optional, that Italk was indeed positively related to neuroticism and anxiety, but only in one of several communication contexts (i.e., a simulated letter of apology). Clearly, important comparative cultural and language research remains to be conducted on this question, and it has the potential to make "the psychology of I-talk" more generalizable, and identify theoretically interesting differences between cultures and languages.

\section{Conclusion}

Rather than reflecting grandiose narcissism, I-talk appears to be correlated with depression, negative emotionality, and vulnerable narcissism. I-talk is also positively correlated with a being female, being young, and having lower rank. These associations point to I-talk being related to diminished (rather than enhanced) social status. In light of these findings, we think that I-talk reflects a kind of self-focus that, at the psychological level, implies vulnerability 
and negative affectivity. For this reason, we speculate that de-centering (e.g., Nook et al., 2020) might help alleviate some of the negative affect (e.g., anxiety, worry) associated with excessive self-focus.

Future work is needed to study (a) how more narrow personality constructs — such as personality facets_-are related to I-talk, (b) how within-person processes are related to I-talk, and (c) how the context might moderate the associations we have highlighted, including culture and communication contexts. All told, the story of I-talk is a fascinating tale of how research literatures develop and how some common-sense intuitions such as the assumed strong association between I-talk and grandiose narcissism turn out to be empirically unsupported. 


\section{Suggested Readings}

Carey, A. L., Brucks, M. S., Kufner, A. C. P., Holtzman, N. S., Deters, F. G., Back, M. D., Donnellan, M. B., Pennebaker, J. W., \& Mehl, M. R. (2015). Narcissism and the use of personal pronouns revisited. Journal of Personality and Social Psychology, 109(3), E1E15. https://doi.org/10.1037/pspp0000029

Edwards, T., \& Holtzman, N. S. (2017). A meta-analysis of correlations between depression and first person singular pronoun use. Journal of Research in Personality, 68, 6368. https://doi.org/10.1016/i.jrp.2017.02.005

Ireland, M. E., \& Mehl, M. R. (2014). Natural language use as a marker. The Oxford handbook of language and social psychology, 201-237. https://doi.org/10.1093/oxfordhb/9780199838639.001.0001

Raskin, R., \& Shaw, R. (1988). Narcissism and the use of personal pronouns. Journal of Personality, 56(2), 393-404. https://doi.org/10.1111/j.1467-6494.1988.tb00892.x

Tackman, A. M., Sbarra, D. A., Carey, A. L., Donnellan, M. B., Horn, A. B., Holtzman, N. S., Edwards, T. S., Pennebaker, J. W., \& Mehl, M. R. (2019). Depression, negative emotionality, and self-referential language: A multi-lab, multi-measure, and multilanguage-task research synthesis. Journal of Personality and Social Psychology, 116(5), 817-834. https://doi.org/10.1037/pspp0000187 


\section{References}

Ahadi, S., \& Diener, E. (1989). Multiple determinants and effect size. Journal of Personality and Social Psychology, 56(3), 398. https://doi.org/10.1037/0022-3514.56.3.398

Alban, L. S., \& Groman, W. D. (1976). Neurotic anxiety, pronoun usage and stress. Journal of Clinical Psychology, 32(2), 393-399. https://doi.org/10.1002/10974679(197604)32:2<393::AID-JCLP2270320240>3.0.CO;2-W

Back, M. D., Kufner, A. C. P., Dufner, M., Gerlach, T. M., Rauthmann, J. F., \& Denissen, J. J. A. (2013). Narcissistic Admiration and Rivalry: Disentangling the Bright and Dark Sides of Narcissism. Journal of Personality and Social Psychology, 105(6), 1013-1037. https://doi.org/10.1037/a0034431

Back, M. D., \& Morf, C. C. (2018). Narcissism. In V. Zeigler-Hill \& T. K. Shackelford (Eds.), Encyclopedia of personality and individual differences. Springer.

Baumeister, R. F., \& Vohs, K. D. (2001). Narcissism as addiction to esteem. Psychological Inquiry, 12(4), 206-210.

Beatles, T. (1970). I me mine. On Let it be. Abby Road Studios.

Beck, A. T., Steer, R. A., Ball, R., \& Ranieri, W. F. (1996). Comparison of Beck Depression Inventories-IA and -II in psychiatric outpatients. Journal of Personality Assessment, 67(3), 588-597. https://doi.org/10.1207/s15327752jpa6703_13

Benjamin, D. J., Berger, J. O., Johannesson, M., Nosek, B. A., Wagenmakers, E. J., Berk, R., Bollen, K. A., Brembs, B., Brown, L., Camerer, C., Cesarini, D., Chambers, C. D., Clyde, M., Cook, T. D., De Boeck, P., Dienes, Z., Dreber, A., Easwaran, K., Efferson, C., Fehr, E., Fidler, F., Field, A. P., Forster, M., George, E. I., Gonzalez, R., Goodman, S., Green, E., Green, D. P., Greenwald, A., Hadfield, J. D., Hedges, L. V., Held, L., Ho, T. H., Hoijtink, H., Hruschka, D. J., Imai, K., Imbens, G., Ioannidis, J. P. A., Jeon, M., Jones, J. 
H., Kirchler, M., Laibson, D., List, J., Little, R., Lupia, A., Machery, E., Maxwell, S. E., McCarthy, M., Moore, D., Morgan, S. L., Munafo, M., Nakagawa, S., Nyhan, B., Parker, T. H., Pericchi, L., Perugini, M., Rouder, J., Rousseau, J., Savalei, V., Schonbrodt, F. D., Sellke, T., Sinclair, B., Tingley, D., Van Zandt, T., Vazire, S., Watts, D. J., Winship, C., Wolpert, R. L., Xie, Y., Young, C., Zinman, J., \& Johnson, V. E. (2018). Redefine statistical significance. Nature Human Behaviour, 2(1), 6-10. https://doi.org/10.1038/s41562-017-0189-Z

Bernard, J. D., Baddeley, J. L., Rodriguez, B. F., \& Burke, P. A. (2016). Depression, Language, and Affect: An Examination of the Influence of Baseline Depression and Affect Induction on Language. Journal of Language and Social Psychology, 35(3), 317-326. https://doi.org/10.1177/0261927x15589186

Brockmeyer, T., Zimmermann, J., Kulessa, D., Hautzinger, M., Bents, H., Friederich, H.-C., Herzog, W., \& Backenstrass, M. (2015). Me, myself, and I: self-referent word use as an indicator of self-focused attention in relation to depression and anxiety. Frontiers in Psychology, 6(1564). https://doi.org/10.3389/fpsyg.2015.01564

Brown, B. (2015). Daring greatly: How the courage to be vulnerable transforms the way we live, love, parent, and lead. Penguin.

Buss, D. M., \& Chiodo, L. M. (1991). Narcissistic acts in everyday life. Journal of Personality, 59(2), 179-215.

Buttice, V., \& Rovelli, P. (2020). "Fund me, I am fabulous!" Do narcissistic entrepreneurs succeed or fail in crowdfunding? Personality and Individual Differences, 162. https://doi.org/10.1016/j.paid.2020.110037 
Campbell, W. K., \& Campbell, S. M. (2009). On the self-regulatory dynamics created by the peculiar benefits and costs of narcissism: A contextual reinforcement model and examination of leadership. Self and Identity, 8(2-3), 214-232. https://doi.org/10.1080/15298860802505129

Campbell, W. K., \& Miller, J. D. (Eds.). (2011). The Handbook of Narcissism and Narcissistic Personality Disorder: Theoretical approaches, empirical findings, and treatments (1st ed.).

Capalbo, F., Frino, A., Lim, M. Y., Mollica, V., \& Palumbo, R. (2018). The Impact of CEO Narcissism on Earnings Management. Abacus-a Journal of Accounting Finance and Business Studies, 54(2), 210-226. https://doi.org/10.1111/abac.12116

Carey, A. L., Brucks, M. S., Kufner, A. C. P., Holtzman, N. S., Deters, F. G., Back, M. D., Donnellan, M. B., Pennebaker, J. W., \& Mehl, M. R. (2015). Narcissism and the Use of Personal Pronouns Revisited. Journal of Personality and Social Psychology, 109(3), E1E15. https://doi.org/10.1037/pspp0000029

Carlson, E. N., Vazire, S., \& Oltmanns, T. F. (2011). You probably think this paper's about you: Narcissists' perceptions of their personality and reputation. Journal of Personality and Social Psychology, 101(1), 185-201. https://doi.org/10.1037/a0023781

Cary, M. (2009, June 9). Barack Obama Journeys From "Yes We Can" to the Imperial "I". The Jefferson Street blog. https://www.usnews.com/opinion/blogs/mary-katecary/2009/06/09/barack-obama-journeys-from-yes-we-can-to-the-imperial-i

Cassell, J., Huffaker, D., Tversky, D., \& Ferriman, K. (2006). The language of online leadership: Gender and youth engagement on the Internet. Developmental psychology, 42(3), 436. https://doi.org/10.1037/0012-1649.42.3.436 
Chatterjee, A., \& Hambrick, D. C. (2007). It's all about me: Narcissistic chief executive officers and their effects on company strategy and performance. Administrative Science Quarterly, 52(3), 351-386. https://doi.org/10.2189/asqu.52.3.351

Cohn, M. A., Mehl, M. R., \& Pennebaker, J. W. (2004). Linguistic Markers of Psychological Change Surrounding September 11, 2001. Psychological Science, 15(10), 687-693. https://doi.org/10.1111/j.0956-7976.2004.00741.x

Czarna, A. Z., Wrobel, M., Folger, L. F., Holtzman, N. S., Raley, J. R., \& Foster, J. D. (in press). Narcissism and Narcissistic Personality Disorder: Evolutionary Roots and Emotional Profiles. In L. Al-Shawaf \& T. K. Shackelford (Eds.), The Oxford Handbook of Evolution and the Emotions. Oxford University Press.

DeWall, C. N., Buffardi, L. E., Bonser, I., \& Campbell, W. K. (2011). Narcissism and implicit attention seeking: Evidence from linguistic analyses of social networking and online presentation. Personality and Individual Differences, 51(1), 57-62. https://doi.org/10.1016/j.paid.2011.03.011

DeWall, C. N., Pond, R. S., Jr., Campbell, W. K., \& Twenge, J. M. (2011). Tuning in to Psychological Change: Linguistic Markers of Psychological Traits and Emotions Over Time in Popular US Song Lyrics. Psychology of Aesthetics Creativity and the Arts, 5(3), 200-207. https://doi.org/10.1037/a0023195

DeYoung, C. G., Quilty, L. C., \& Peterson, J. B. (2007). Between facets and domains: 10 aspects of the Big Five. Journal of Personality and Social Psychology, 93(5), 880.

Dixon, A., McGinnis, B., Holtzman, N. S., Dorough, H., \& Donnellan, M. B. (2020). Vulnerable narcissism and first-person singular pronoun usage [Poster Presentation]. Society for Personality and Social Psychology, New Orleans, LA, United States. 
Dowgwillo, E. A., \& Pincus, A. L. (2017). Differentiating Dark Triad Traits Within and Across Interpersonal Circumplex Surfaces. Assessment, 24(1), 24-44. https://doi.org/10.1177/1073191116643161

Dozois, D. J. A., Dobson, K. S., \& Ahnberg, J. L. (1998). A psychometric evaluation of the Beck Depression Inventory - II. Psychological Assessment, 10(2), 83-89. https://doi.org/10.1037/1040-3590.10.2.83

Edwards, T., \& Holtzman, N. S. (2017). A meta-analysis of correlations between depression and first person singular pronoun use. Journal of Research in Personality, 68, 63-68. https://doi.org/10.1016/j.jrp.2017.02.005

Eichstaedt, J. C., Smith, R. J., Merchant, R. M., Ungar, L. H., Crutchley, P., Preoţiuc-Pietro, D., Asch, D. A., \& Schwartz, H. A. (2018). Facebook language predicts depression in medical records. Proceedings of the National Academy of Sciences, 115(44), 1120311208. https://doi.org/10.1073/pnas.1802331115

Elleman, L. G., Condon, D. M., Holtzman, N. S., Allen, V. R., \& Revelle, W. (2020). Smaller Is Better: Associations Between Personality and Demographics Are Improved by Examining Narrower Traits and Regions. Collabra: Psychology, 6(1). https://doi.org/10.1525/collabra.17210

Fast, L. A., \& Funder, D. C. (2010). Gender Differences in the Correlates of Self-Referent Word Use: Authority, Entitlement, and Depressive Symptoms. Journal of Personality, 78(1), 313-338. https://doi.org/10.1111/j.1467-6494.2009.00617.x

Fredrickson, B. L. (2001). The role of positive emotions in positive psychology: the broadenand-build theory of positive emotions. American Psychologist, 56(3), 218-226. 
Funder, D. C., \& Ozer, D. J. (2019). Evaluating effect size in psychological research: Sense and nonsense. Advances in Methods and Practices in Psychological Science, 2(2), 156-168.

Goodman, R. (2017). William James. The Stanford Encyclopedia of Philosophy. https://plato.stanford.edu/cgi-bin/encyclopedia/archinfo.cgi?entry=james

Grossmann, I., Dorfman, A., Oakes, H., Santos, H. C., Vohs, K. D., \& Scholer, A. A. (in press). Training for Wisdom: The Distanced-Self-Reflection Diary Method. Psychological Science, O(0), 0956797620969170. https://doi.org/10.1177/0956797620969170

Guntuku, S. C., Schwartz, H. A., Kashyap, A., Gaulton, J. S., Stokes, D. C., Asch, D. A., Ungar, L. H., \& Merchant, R. M. (2020). Variability in Language used on Social Media prior to Hospital Visits. Scientific Reports, 10(1), 4346. https://doi.org/10.1038/s41598-020$\underline{60750-8}$

Hancock, J. T., Curry, L. E., Goorha, S., \& Woodworth, M. (2007). On lying and being lied to: A linguistic analysis of deception in computer-mediated communication. Discourse Processes, 45(1), 1-23. https://doi.org/10.1080/01638530701739181

Hancock, J. T., Woodworth, M., \& Boochever, R. (2018). Psychopaths online: The linguistic traces of psychopathy in email, text messaging and Facebook. Media and Communication, 6(3), 83-92. https://doi.org/10.17645/mac.v6i3.1499

Hauch, V., Blandon-Gitlin, I., Masip, J., \& Sporer, S. L. (2015). Are Computers Effective Lie Detectors? A Meta-Analysis of Linguistic Cues to Deception. Personality and Social Psychology Review, 19(4), 307-342. https://doi.org/10.1177/1088868314556539

Hendin, H. M., \& Cheek, J. M. (1997). Assessing Hypersensitive Narcissism: A Reexamination of Murray's Narcism Scale. Journal of Research in Personality, 31(4), 588-599. https://doi.org/https://doi.org/10.1006/jrpe.1997.2204 
Hill, P. L., \& Roberts, B. W. (2011). Narcissism, Well-Being, and Observer-Rated Personality Across the Lifespan. Social Psychological and Personality Science, 3(2), 216-223. https://doi.org/10.1177/1948550611415867

Hill, P. L., \& Roberts, B. W. (2018). Narcissism as a life span construct: describing fluctuations using new approaches. In Handbook of Trait Narcissism (pp. 165-172). Springer. https://www.springer.com/gp/book/9783319921709\#aboutBook

Holtzman, N. S., Tackman, A. M., Carey, A. L., Brucks, M. S., Kufner, A. C. P., Deters, F. G., Back, M. D., Donnellan, M. B., Pennebaker, J. W., Sherman, R. A., \& Mehl, M. R. (2019). Linguistic Markers of Grandiose Narcissism: A LIWC Analysis of 15 Samples. Journal of Language and Social Psychology, 38(5-6), 773-786. https://doi.org/10.1177/0261927x19871084

Ireland, M. E., \& Mehl, M. R. (2014). Natural language use as a marker. The Oxford handbook of language and social psychology, 201-237. https://doi.org/10.1093/oxfordhb/9780199838639.001.0001

James, W. (1890). The Principles of Psychology. Henry Holt and Company.

Jones, D. N., \& Paulhus, D. L. (2014). Introducing the Short Dark Triad ( SD3): A Brief Measure of Dark Personality Traits. Assessment, 21(1), 28-41. https://doi.org/10.1177/1073191113514105

Kacewicz, E., Pennebaker, J. W., Davis, M., Jeon, M., \& Graesser, A. C. (2013). Pronoun Use Reflects Standings in Social Hierarchies. Journal of Language and Social Psychology, 33(2), 125-143. https://doi.org/10.1177/0261927X13502654

Kern, M. L., Eichstaedt, J. C., Schwartz, H. A., Dziurzynski, L., Ungar, L. H., Stillwell, D. J., Kosinski, M., Ramones, S. M., \& Seligman, M. E. P. (2013). The Online Social Self: An 
Open Vocabulary Approach to Personality. Assessment, 21(2), 158-169. https://doi.org/10.1177/1073191113514104

Kern, M. L., Eichstaedt, J. C., Schwartz, H. A., Park, G., Ungar, L. H., Stillwell, D. J., Kosinski, M., Dziurzynski, L., \& Seligman, M. E. P. (2014). From "Sooo Excited!!!" to "So Proud": Using Language to Study Development. Developmental Psychology, 50(1), 178188. https://doi.org/10.1037/a0035048

Klauke, F., \& Kauffeld, S. (2020). Does It Matter What I Say? Using Language to Examine Reactions to Ostracism as It Occurs. Frontiers in Psychology, 11(3097). https://doi.org/10.3389/fpsyg.2020.558069

Krejtz, I., Rohnka, N., Holas, P., Rusanowska, M., \& Nezlek, J. B. (2020). Manifestations of clinical depression in daily life: a daily diary study of descriptions of naturally occurring events. Cognition \& Emotion, 34(8), 1664-1675. https://doi.org/10.1080/02699931.2020.1795627

Krizan, Z., \& Herlache, A. D. (2018). The Narcissism Spectrum Model: A Synthetic View of Narcissistic Personality. Personality and Social Psychology Review, 22(1), 3-31. https://doi.org/10.1177/1088868316685018

Kross, E., Bruehlman-Senecal, E., Park, J., Burson, A., Dougherty, A., Shablack, H., Bremner, R., Moser, J., \& Ayduk, O. (2014). Self-talk as a regulatory mechanism: How you do it matters. Journal of Personality and Social Psychology, 106(2), 304-324. https://doi.org/10.1037/a0035173

Kučera, D. (2020). Osobnostní markery v textu [Personality markers in text].

Kučera, D., Havigerová, J. M., Haviger, J., Cvrček, V., Komrsková, Z., Lukeš, D., Jelínek, T., Urbánek, T., \& Franková, J. (2018). Výzkum CPACT: Komputační psycholingvistická 
analýza českého textu [CPACT Research: Computational Psycholinguistic Analysis of Czech Text]. Č. Budějovice: Pedagogická fakulta Jihočeské univerzity v Českých Budějovicích.

Liberman, M. (2009, 08 June 2009). Obama's Imperial "I": spreading the meme. https://languagelog.ldc.upenn.edu/nll/?p=1488

Liberman, M. (2014, 21 October 2014). Buzzfeed linguistics, presidential pronouns, and narcissism revisited. https://languagelog.ldc.upenn.edu/nll/?p=15355

Lyons, M., Aksayli, N. D., \& Brewer, G. (2018). Mental distress and language use: Linguistic analysis of discussion forum posts. Computers in Human Behavior, 87, 207-211. https://doi.org/10.1016/j.chb.2018.05.035

Malone, T. (2014). The authentic I: authenticity in first-person narrative journalism [University of Missouri--Columbia]]. https://mospace.umsystem.edu/xmlui/bitstream/handle/10355/44304/research.pdf?sequen $\underline{\mathrm{ce}=1}$

Markus, H. R., \& Kitayama, S. (1991). Culture and the self: Implications for cognition, emotion, and motivation. Psychological Review, 98(2), 224-253. https://doi.org/10.1037/0033295x.98.2.224

McAdams, D. P. (1995). What do we know when we know a person? Journal of Personality, 63(3), 365-396. https://doi.org/10.1111/j.1467-6494.1995.tb00500.x

McWhorter, J. (2017). Why the right thinks Obama's a narcissist--and why they're wrong. Daily Beast. https://www.thedailybeast.com/why-the-right-thinks-obamas-a-narcissistand-whytheyre-wrong 
Mead, G. H. (1934). Mind, Self, and Society (C. W. Morris, Ed.). The University of Chicago Press. https://doi.org/http://tankona.free.fr/mead1934.pdf

Mehl, M. R., Robbins, M. L., \& Holleran, S. E. (2012). How taking a word for a word can be problematic: Context-dependent linguistic markers of extraversion and neuroticism. Journal of Methods and Measurement in the Social Sciences, 3(2), 30-50. https://doi.org/10.2458/v3i2.16477

Miller, J. D., Hoffman, B. J., Gaughan, E. T., Gentile, B., Maples, J., \& Campbell, W. K. (2011). Grandiose and Vulnerable Narcissism: A Nomological Network Analysis. Journal of Personality, 79(5), 1013-1042. https://doi.org/10.1111/j.1467-6494.2010.00711.x

Miller, J. D., Lynam, D. R., Hyatt, C. S., \& Campbell, W. K. (2017). Controversies in Narcissism. Annual Review of Clinical Psychology, 13(1), 291-315. https://doi.org/10.1146/annurev-clinpsy-032816-045244

Miller, J. D., Lynam, D. R., Vize, C., Crowe, M., Sleep, C., Maples-Keller, J. L., Few, L. R., \& Campbell, W. K. (2018). Vulnerable narcissism is (mostly) a disorder of neuroticism. Journal of Personality, 86(2), 186-199. https://doi.org/10.1111/jopy.12303

Newman, M. L., Groom, C. J., Handelman, L. D., \& Pennebaker, J. W. (2008). Gender differences in language use: An analysis of 14,000 text samples [Article]. Discourse Processes, 45(3), 211-236. https://doi.org/10.1080/01638530802073712

Newman, M. L., Pennebaker, J. W., Berry, D. S., \& Richards, J. M. (2003). Lying words: Predicting deception from linguistic styles. Personality and Social Psychology Bulletin, 29(5), 665-675. https://doi.org/10.1177/0146167203029005010 
Nook, E. C., Bustamante, C. M. V., Cho, H. Y., \& Somerville, L. H. (2020). Use of Linguistic Distancing and Cognitive Reappraisal Strategies During Emotion Regulation in Children, Adolescents, and Young Adults. Emotion, 20(4). https://doi.org/10.1037/emo0000570

O'Dea, B., Larsen, M. E., Batterham, P. J., Calear, A. L., \& Christensen, H. (2017). A Linguistic Analysis of Suicide-Related Twitter Posts. Crisis-the Journal of Crisis Intervention and Suicide Prevention, 38(5), 319-329. https://doi.org/10.1027/0227-5910/a000443

Orvell, A., Ayduk, O., Moser, J. S., Gelman, S. A., \& Kross, E. (2019). Linguistic Shifts: A Relatively Effortless Route to Emotion Regulation? Current Directions in Psychological Science, 28(6), 567-573. https://doi.org/10.1177/0963721419861411

Park, G., Schwartz, H. A., Eichstaedt, J. C., Kern, M. L., Kosinski, M., Stillwell, D. J., Ungar, L. H., \& Seligman, M. E. (2015). Automatic personality assessment through social media language. Journal of Personality and Social Psychology, 108(6), 934. https://doi.org/10.1037/pspp0000020

Paulhus, D. L. (2001). Normal narcissism: Two minimalist accounts. Psychological Inquiry, 12(4), 228-230.

Paulhus, D. L., \& Williams, K. M. (2002). The Dark Triad of personality: Narcissism, Machiavellianism, and psychopathy. Journal of Research in Personality, 36(6), 556-563. https://doi.org/10.1016/s0092-6566(02)00505-6

Pennebaker, J. W., \& King, L. A. (1999). Linguistic styles: language use as an individual difference. Journal of Personality and Social Psychology, 77(6), 1296.

Pennebaker, J. W., \& Stone, L. D. (2003). Words of wisdom: Language use over the life span. Journal of Personality and Social Psychology, 85(2), 291-301. https://doi.org/10.1037/0022-3514.85.2.291 
Quoidbach, J., Berry, E. V., Hansenne, M., \& Mikolajczak, M. (2010). Positive emotion regulation and well-being: Comparing the impact of eight savoring and dampening strategies. Personality and Individual Differences, 49(5), 368-373. https://doi.org/10.1016/j.paid.2010.03.048

Radloff, L. S. (1977). The CES-D scale: A self-report depression scale for research in the general population. Applied Psychological Measurement, 1(3), 385-401.

Raskin, R., \& Hall, C. S. (1981). The Narcissistic Personality Inventory - Alternate form reliability and further evidence of construct-validity. Journal of Personality Assessment, 45(2), 159-162. https://doi.org/10.1207/s15327752jpa4502_10

Raskin, R., \& Shaw, R. (1988). Narcissism and the use of personal pronouns. Journal of Personality, 56(2), 393-404. https://doi.org/10.1111/j.1467-6494.1988.tb00892.x

Raskin, R., \& Terry, H. (1988). A principal-components analysis of the Narcissistic Personality Inventory and further evidence of its construct-validity. Journal of Personality and Social Psychology, 54(5), 890-902. https://doi.org/10.1037/0022-3514.54.5.890

Raskin, R. N., \& Hall, C. S. (1979). Narcissistic Personality Inventory. Psychological Reports, 45(2), 590-590. https://doi.org/10.2466/pr0.1979.45.2.590

Roberts, B. W., Luo, J., Briley, D. A., Chow, P. I., Su, R., \& Hill, P. L. (2017). A Systematic Review of Personality Trait Change Through Intervention. Psychological Bulletin, 143(2), 117-+. https://doi.org/10.1037/bul0000088

Robins, R. W., \& John, O. P. (1997). Effects of visual perspective and narcissism on selfperception: Is seeing believing? Psychological Science, 8(1), 37-42. https://doi.org/10.1111/j.1467-9280.1997.tb00541.x 
Schonbrodt, F. D., \& Perugini, M. (2013). At what sample size do correlations stabilize? Journal of Research in Personality, 47(5), 609-612. https://doi.org/10.1016/j.jrp.2013.05.009

Sedikides, C. (2020). On the doggedness of self-enhancement and self-protection: How constraining are reality constraints? Self and Identity, 19(3), 251-271. https://doi.org/10.1080/15298868.2018.1562961

Seraj, S., Blackburn, K. G., \& Pennebaker, J. W. (2021). Language left behind on social media exposes the emotional and cognitive costs of a romantic breakup. Proceedings of the National Academy of Sciences, 118(7), e2017154118. https://doi.org/10.1073/pnas.2017154118

Silvia, P. J., \& Duval, T. S. (2001). Objective self-awareness theory: Recent progress and enduring problems. Personality and Social Psychology Review, 5(3), 230-241. https://doi.org/10.1207/s15327957pspr0503_4

Smith, T. W., \& Greenberg, J. (1981). Depression and self-focused attention. Motivation and emotion, 5(4), 323-331.

Stirman, S. W., \& Pennebaker, J. W. (2001). Word use in the poetry of suicidal and nonsuicidal poets. Psychosomatic Medicine, 63(4), 517-522. https://journals.1ww.com/psychosomaticmedicine/Fulltext/2001/07000/Word_Use_in_the _Poetry_of_Suicidal_and_Nonsuicidal.1.aspx?casa_token=5yy1L3TR_MAAAAA:M1ZsyLmmzQPukMJDAYXm0erTMgjA4FKMdNE1r0AN9GBavD6irFZLP2w7Ph1j6X6 SyuUvGs_PQ-WpGRa0I-wbbvm

Sun, J., Schwartz, H. A., Son, Y., Kern, M. L., \& Vazire, S. (2020). The Language of WellBeing: Tracking Fluctuations in Emotion Experience Through Everyday Speech. Journal 
of Personality and Social Psychology, 118(2), 364-387. https://doi.org/10.1037/pspp0000244

Tackman, A. M., Baranski, E. N., Danvers, A. F., Sbarra, D. A., Raison, C. L., Moseley, S. A., Polsinelli, A. J., \& Mehl, M. R. (2020). 'Personality in Its Natural Habitat' Revisited: A Pooled, Multi-sample Examination of the Relationships Between the Big Five Personality Traits and Daily Behaviour and Language Use. European journal of personality, 34(5), 753-776. https://doi.org/https://doi.org/10.1002/per.2283

Tackman, A. M., Sbarra, D. A., Carey, A. L., Donnellan, M. B., Horn, A. B., Holtzman, N. S., Edwards, T. S., Pennebaker, J. W., \& Mehl, M. R. (2019). Depression, Negative Emotionality, and Self-Referential Language: A Multi-Lab, Multi-Measure, and MultiLanguage-Task Research Synthesis. Journal of Personality and Social Psychology, 116(5), 817-834. https://doi.org/10.1037/pspp0000187

Thomaes, S., Bushman, B. J., Orobio de Castro, B., \& Stegge, H. (2009). What makes narcissists bloom? A framework for research on the etiology and development of narcissism. Development and Psychopathology, 21, 1233-1247. https://doi.org/10.1017/S0954579409990137

Van Scotter II, J. R. (2020). Narcissism in CEO research: a review and replication of the archival approach. Management Review Quarterly, 70(4), 629-674. https://doi.org/10.1007/s11301-019-00178-1

W.H.O. (2020). https://www.who.int/news-room/fact-sheets/detail/depression

Weiser, E. B. (2015). \#Me: Narcissism and its facets as predictors of selfie-posting frequency. Personality and Individual Differences, 86, 477-481. https://doi.org/10.1016/j.paid.2015.07.007 
Wicklund, R. A., \& Duval, S. (1971). Opinion change and performance facilitation as a result of objective self-awareness. Journal of Experimental Social Psychology, 7(3), 319-\&. https://doi.org/10.1016/0022-1031(71)90032-1

Widiger, T. A., \& Oltmanns, J. R. (2017). Neuroticism is a fundamental domain of personality with enormous public health implications. World Psychiatry, 16(2), 144-145. https://doi.org/10.1002/wps.20411

Wink, P. (1991). Two faces of narcissism. Journal of Personality and Social Psychology, 61(4), 590-597. http://academics.wellesley.edu/Psychology/Wink/Two\%20faces\%20of\%20Narcissism.pd $\underline{f}$

Wright, A. G., \& Edershile, E. A. (2018). Issues resolved and unresolved in pathological narcissism. Current Opinion in Psychology, 21, 74-79. https://doi.org/10.1016/j.copsyc.2017.10.001

Yang, M. H., Ramiah, V., Moosa, I., \& He, Y. (2018). Narcissism, political tenure, financial indicators and the effectiveness of environmental regulation. Applied Economics, 50(21), 2325-2338. https://doi.org/10.1080/00036846.2017.1394977

Yarkoni, T. (2010). Personality in 100,000 words: A large-scale analysis of personality and word use among bloggers. Journal of Research in Personality, 44(3), 363-373. https://doi.org/10.1016/j.jrp.2010.04.001 


\section{Figure 1.}

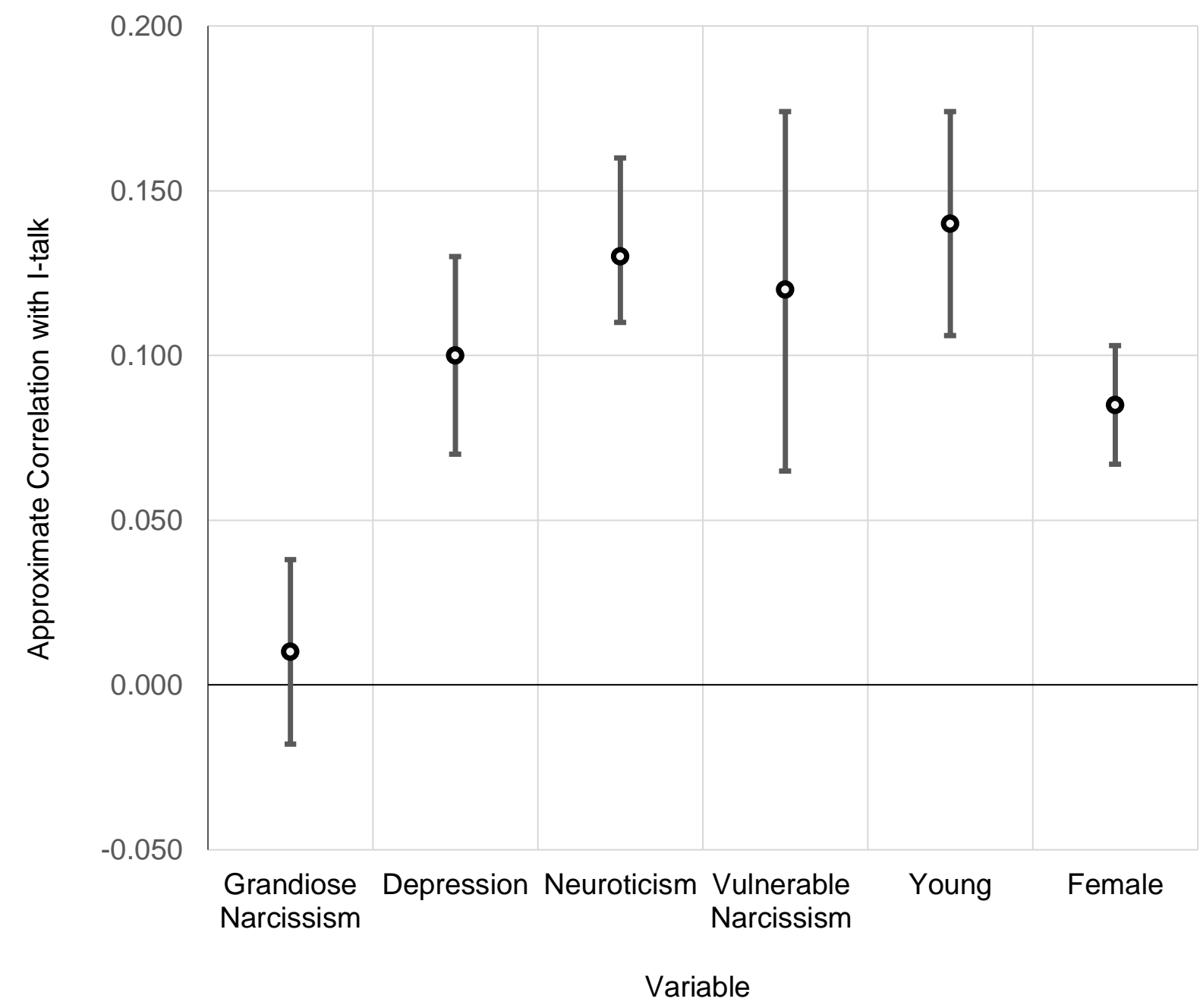

Figure 1. Approximate correlations between key variables and I-talk, with $95 \%$ confidence intervals. This figure shows the near-zero correlation between grandiose narcissism and I-talk, while it shows the positive correlations between the other constructs and I-talk. All of these estimates are based on sample sizes over 1,000 and therefore the CIs are narrow. The grandiose narcissism association is from Carey et al. (2015); the depression and neuroticism correlations are from Tackman et al. (2019); the vulnerable narcissism association is from Dixon et al. (2020). Young $=$ the reverse of age, so the effect indicates that young people use more I-talk than older people. Female $=$ an (oversimplified) binary variable for female $($ coded +1.0$)$ and male (coded -1.0$)$; the positive relationship indicates that women use more I-talk than men. The Young association is from Pennebaker and Stone (2003, Table 2, simple $r$ ), and, for corroborating findings, see Kern et al. (Kern et al., 2014); the Female variable is from Newman et al. (2008, Table 1; $0.17 \mathrm{~d}$ converted to Pearon's $r$ ). 